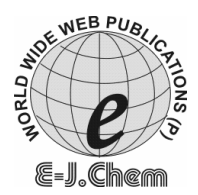

http://www.e-journals.net
ISSN: 0973-4945; CODEN ECJHAO

E-Journal of Chemistry

Vol. 5, No.4, pp. 904-913, October 2008

\title{
Study of Curing Kinetics and Thermal Degradation of UV Curable Epoxy Acrylate Resin
}

\author{
AMRITA SHARMA*§, DEVENDRA AGARWAL ${ }^{\S}$ \\ and JAGABIR SINGH ${ }^{\#}$ \\ ${ }^{\S}$ Department of Oil \& Paint Technology, \\ H.B. Technological Institute, Kanpur - 208002, UP, India. \\ \#Jubilant Organosys Ltd. Plot 1A, Sector 16, Noida - 201301. \\ sharma_amrita@rediffmail.com, Fax: +915122501541
}

Received 22 January 2008; Accepted 20 March 2008

\begin{abstract}
Blends of epoxy acrylate resins (acid values 3, 6.5 \& $10 \mathrm{mg} \mathrm{KOH} / \mathrm{gm}$ Solid) with monofunctional monomers (ethoxylated phenol monoacrylate) were prepared by physical mixing, having weight ratio 50:50. These blends were cured by using UV radiations in presence of photo initiator (Darocure 1173). The thermal degradation kinetics of these resin blends were studied, using thermo gravimetric analysis in nitrogen atmosphere at a heating rate of $10^{\circ} \mathrm{C} / \mathrm{min}$. by applying CoatsRed fern equation. According to the analysis, all the coating films degrade in two steps. In the first step of degradation kinetics, $\mathrm{R}_{2} \mathrm{M}$ follows 1.75 order $(\mathrm{n}=1.75)$ and all other coating films follow second order $(n=2)$ kinetics. In second step, $\mathrm{R}_{2} \mathrm{M} \&$ $\mathrm{R}_{3} \mathrm{M}$ follow half order $(n=0.5)$ kinetics and $\mathrm{R}_{1} \mathrm{M}$ follow first order $(n=1)$ degradation kinetics. Order of the reaction is obtained on the basis of best fit analysis, and all the parameters were confirmed by regression analysis. From the reaction order, value of activation energy $(\mathrm{E})$ and pre exponential factor $(\mathrm{Z})$ were calculated by the slop and intercept of the plot between $\mathrm{X}$ and $\mathrm{Y}$, respectively.
\end{abstract}

Keywords: Epoxy acrylate, Thermal properties, Acid value, UV curing, Degradation kinetics

\section{Introduction}

Epoxy acrylate resins are commercially used in coatings and various structural applications. By proper selection of epoxy acrylate resin and monomers, the cured thermosetting product can be tailored to specific performance characteristics. The choice depends upon the cost, processing and performance requirement. Cured epoxy acrylate resins exhibit excellent adhesion to a 
variety of substrates, good chemical and corrosion resistance, excellent electrical insulation, high tensile, flexural strength, good compressive strength and thermal stability. The largest single use is in coatings, where high chemical, corrosion resistance and adhesion are important. The exceptional adhesion performance is due to the presence of polar hydroxyl and ether groups in the backbone structure of epoxy resins ${ }^{1-3}$. The presence of unsaturation at the end of the polymer backbone (due to reaction with acid functional acrylic monomers) has shaped epoxy resins for the radiation curing industry. Terminal unsaturated double bonds are the reactive sites for coatings and paints ${ }^{4-6}$. Unsaturated monofunctional, multifunctional acrylated monomer and acrylated oligomer having epoxy backbone are capable of a rational designed formulation that provides good coating properties after curing.

In general, the UV curing process results in three dimensional network formations. The curing process is fast and depends on the radiation dose and the time of radiation ${ }^{7}$. UV curing, i.e., the process of photo initiated conversion of polymeric materials from a liquid to a solid is a popular alternative to conventional thermal curing 8 . UV curing systems had recently succeeded in a large number of new applications and expanded toward new markets ${ }^{9-11}$. Many of these become possible because of the development of new UV-curable system that is commercially available ${ }^{12}$. UV curing process has attractive advantages over thermal curing. Its major advantages are high-speed process, low energy consumption (as the operation at room temperature), and environmental friendly as there is no solvent exposure ${ }^{13}$. Generally, UVcurable formulations contain oligomer or prepolymer consisting of reactive sites based on a functional acrylate group to meet the VOC compliance ${ }^{14}$. Several researchers ${ }^{15-18}$ studied the thermal degradation mechanism of different products.

In this study, epoxy resins were reacted with acrylic acid. The acrylated oligomer were mixed with ethoxylated phenol monoacrylate and cured by UV radiation. The aim of this study was to analyze the effect on the thermal properties of polymeric film due to the presence of Epoxy acrylate resins of different acid values and monofunctional monomer.

\section{Experimental}

\section{Materials}

Epoxy resin (M/S Parik Resin), acrylic acid (M/S), triethyl amine (M/S), ethoxylated phenol monoacrylate (M/S Cognis), Darocure 1173 (Ciba Specialty Chemical), ethyl alcohol (Ranbaxy Laboratories Ltd.), $\mathrm{NaOH}$ (E. Merck), $\mathrm{H}_{2} \mathrm{SO}_{4}$ (S.D. Fine Chemicals) were used during the Investigation.

\section{Preparation of epoxy acrylate resin}

Epoxy acrylate resins $\mathrm{R}_{1}, \mathrm{R}_{2} \& \mathrm{R}_{3}$ of acid values $3,6.5 \& 10 \mathrm{mg} \mathrm{KOH} / \mathrm{gm}$ solid respectively were prepared using 1:1 mole ratio of bisphenol A based Epoxy resin (EEW-180) and acrylic acid in presence of triethyl amine (1 Phr. by wt. of epoxy resin) as catalyst.

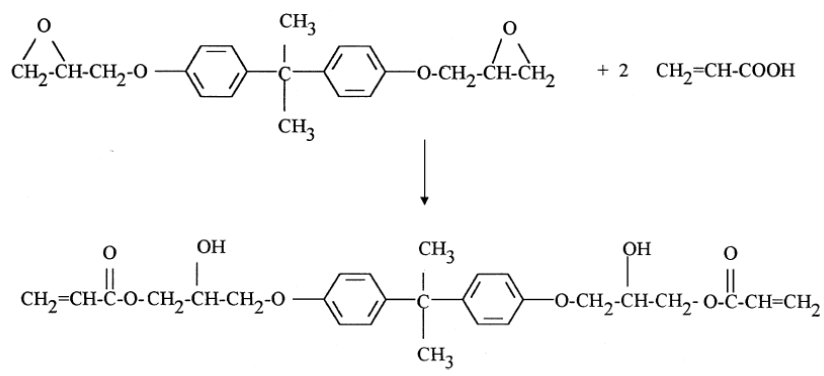




\section{Characterization of epoxy acrylate resin}

\section{Determination of acid value}

The acid value of epoxy acrylate resin was determined according to Karshak and Vinogradova $^{19}$

\section{Extent of reaction}

$$
\begin{aligned}
& \text { Acid value }=56.1 \times(\mathrm{A}-\mathrm{B}) \times \mathrm{N} / \mathrm{W} \\
& \text { Where, } \mathrm{A}=\mathrm{mL} . \text { of } \mathrm{KOH} \text { of sample } \\
& \mathrm{B}=\mathrm{mL} . \text { of } \mathrm{KOH} \text { of blank } \\
& \mathrm{W}=\text { wt. of resin }(\mathrm{g})
\end{aligned}
$$

The extent of reaction ' $p$ ' defined as the fraction of carboxyl group that has reacted in time t, was calculated from the acid value of the resins which a measure of the concentration of carboxyl groups is using following equation:

$$
\begin{aligned}
& \text { Extent of reaction }(\mathrm{P})=1-\mathrm{M} / \mathrm{M}_{0} \\
& \text { where, } \mathrm{M}_{0}=\text { initial acid value } \\
& \mathrm{M}=\text { acid value at time } \mathrm{T}
\end{aligned}
$$

Preparation of blends of epoxy acrylate resin \& mono functional monomer (ethoxylated Phenol monoacrylate)

Epoxy acrylate resins (R1, R2 \& R3) were mixed with ethoxylated phenol monoacrylate (EOPA) with wt ratio 50/50, based on physical mixing. All the samples were designated according to Table 1 . These blends were cured by adding a requisite amount of photo initiator (Darocure 1173) and cured by UV radiations. The degradation kinetics of these blends was studied by thermogravimetric analysis.

The reactive thermal stability of experimental resins was quantitatively estimated by comparing temperatures for a particular degree of weight loss (Thermogravimetric analyzer TGA Q 50 V 6.1 Build 181).

The Coats-Red Fern equation was used to determine the values of the activation energy (E) and pre-exponential factor (Z).

$$
\log _{10}\left[g(\alpha) / T^{2}\right]=\log _{10}[Z R / \beta \text { E }(1-2 R T / E)]-E / 2.303 R T
$$

where, $g(\alpha)=\left\{1-(1-\alpha)^{1-n} / 1-n \quad\right.$ for $n \neq 1-\log _{10}\left\{-\log _{10}(1-\alpha)\right.$ for $n=1$

Equation (1) can be reduce to

$$
\mathrm{Y}=\mathrm{A}+\mathrm{B} / 1000 \mathrm{X}
$$

where, $Y=\log \left[g(\alpha) / T^{2]}\right.$ for different values of $n$ lying between 0 and 2

$\mathrm{X}=1000 / \mathrm{T}$

$\mathrm{A}=\log _{10}[\mathrm{ZR} / \beta \mathrm{E}(1-2 \mathrm{RT} / \mathrm{E}]$

$\mathrm{B}=-\mathrm{E} / 2.303 \mathrm{R}$

$\alpha=\mathrm{W}_{\mathrm{T}}-\mathrm{W}_{\mathrm{f}} / \mathrm{W}_{\mathrm{o}}-\mathrm{W}_{\mathrm{f}}$

where, $\alpha=$ fractional $\mathrm{w}$. loss

$\mathrm{W}_{\mathrm{T}}=\mathrm{Wt}$. at temp. $\mathrm{T}$

$\mathrm{W}_{\mathrm{f}}=$ Final wt.

$\mathrm{W}_{0}=$ Initial $\mathrm{wt}$.

$\mathrm{R}=$ Gas constant

A graph of $\mathrm{X} v s$. Y was plotted on the basis of best fit technique, and the value on $\mathrm{n}$, was calculated. The value of $\mathrm{n}$ was confirmed by regression analysis. The samples have been designated according to the blend of epoxy acrylate resins and mono functional reactive diluent. (Table 1) 
Table 1. Sample designation of various blends sample

\begin{tabular}{cccc}
\hline S. No. & $\begin{array}{c}\text { Epoxy Acrylate } \\
\text { Wt. } \%\end{array}$ & EOPA Wt. \% & $\begin{array}{c}\text { Sample } \\
\text { Designation }^{\mathrm{a}}\end{array}$ \\
\hline 1 & 50 & 50 & $\mathrm{R}_{1} \mathrm{M}$ \\
2 & 50 & 50 & $\mathrm{R}_{2} \mathrm{M}$ \\
3 & 50 & 50 & $\mathrm{R}_{3} \mathrm{M}$ \\
\hline
\end{tabular}

\section{Results and Discussion}

Figure 1 shows the change in the acid value of different epoxy acrylate samples $\left(R_{1}, R_{2} \&\right.$ $\mathrm{R}_{3}$ ) with reaction time. It is apparent from the figure that the acid value decreases with the reaction time. It is apparent from the plot that the decrease in acid value in the initial stages of the reaction is not linear. This is because of high concentration of the reactive sites and greater possibility of association of the acid and epoxide groups.

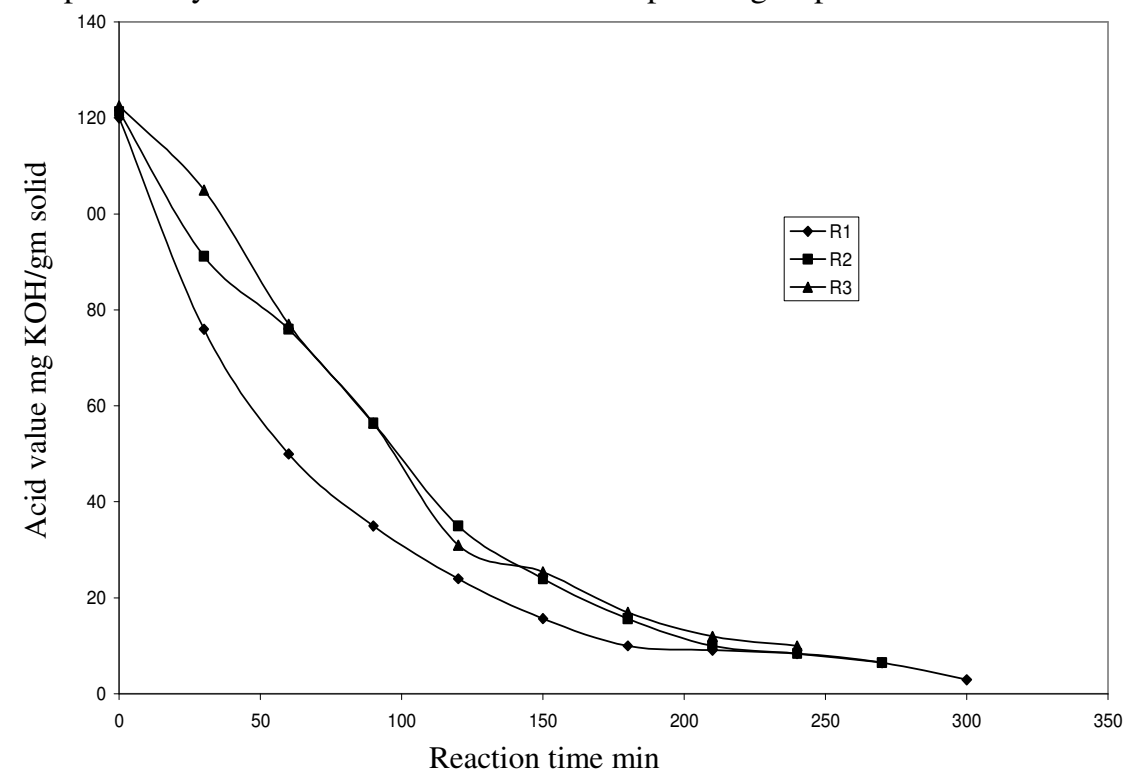

Figure 1. Acid value vs. reaction time

Figure 2 shows the change in extent of reaction ( $p$ ) with time for different epoxy acrylate resin samples $\left(\mathrm{R}_{1}, \mathrm{R}_{2} \& \mathrm{R}_{3}\right)$. It is clear from the plot that the extent of reaction increases with time and at a particular time extent of reaction ( $p$ ) of $\mathrm{R}_{1}$ was found to be more than that of $\mathrm{R}_{2} \& \mathrm{R}_{3}$.

The temperature of 1-10\% wt. loss (Figure 3, $4 \& 5$ ) in the thermogravimetric analysis at program rate of $10^{0} \mathrm{C} \mathrm{min}-1$ for epoxy acrylate resins of different acid values $\left(R_{1}, R_{2} \& R_{3}\right)$ containing EOPA $(50 \% \mathrm{w} / \mathrm{w})$ are given in Table 2 . From the table, it is apparent, that the thermal stability of epoxy acrylate resin having lowest acid value $\left(R_{1}\right)$ was highest.

The kinetic parameter viz., activation energy (E), pre exponential factor $(\mathrm{Z})$ and order of reaction (n) for the thermal decomposition of these blends for all steps have been calculated by thermo gravimetric analysis. The fractional decomposition $(\alpha)$ for the respective temperatures has also been calculated from TGA data (Figure 6, 7, 8, 9, $10 \& 11$ ). The kinetic parameter of thermal decomposition was calculated by using the integral equation of Coats - Red fern. The order of reaction was also calculated from this equation. 


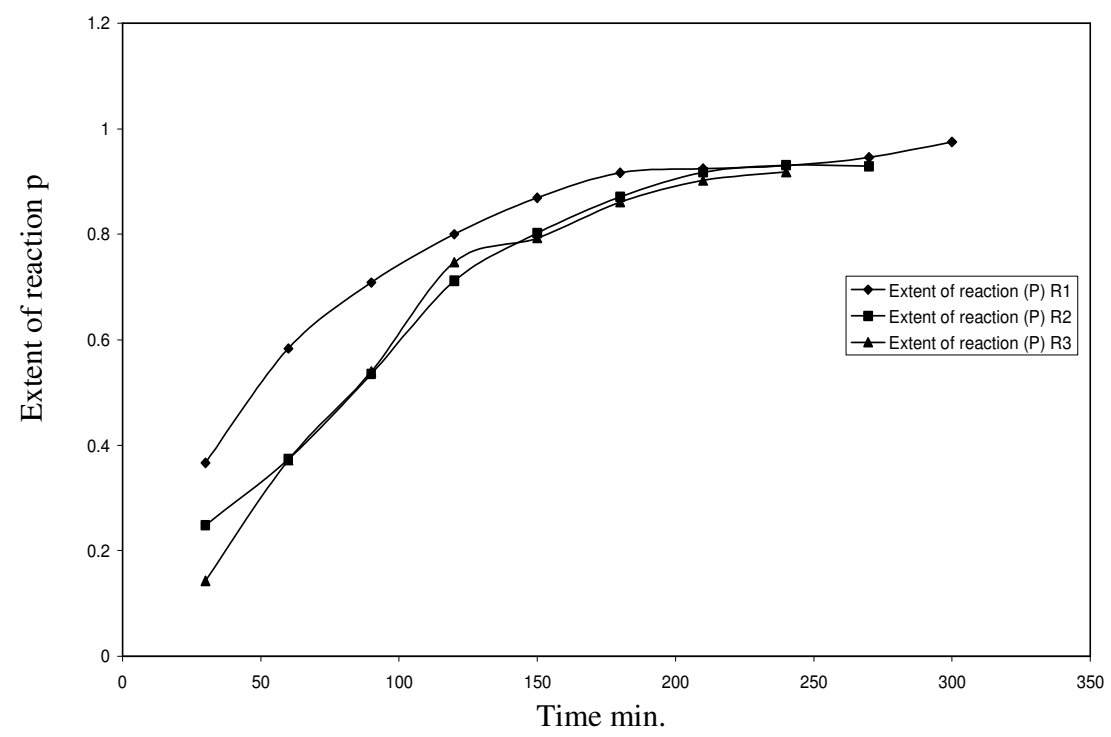

Figure 2. Extent of reaction with time for different epoxy acrylate resin

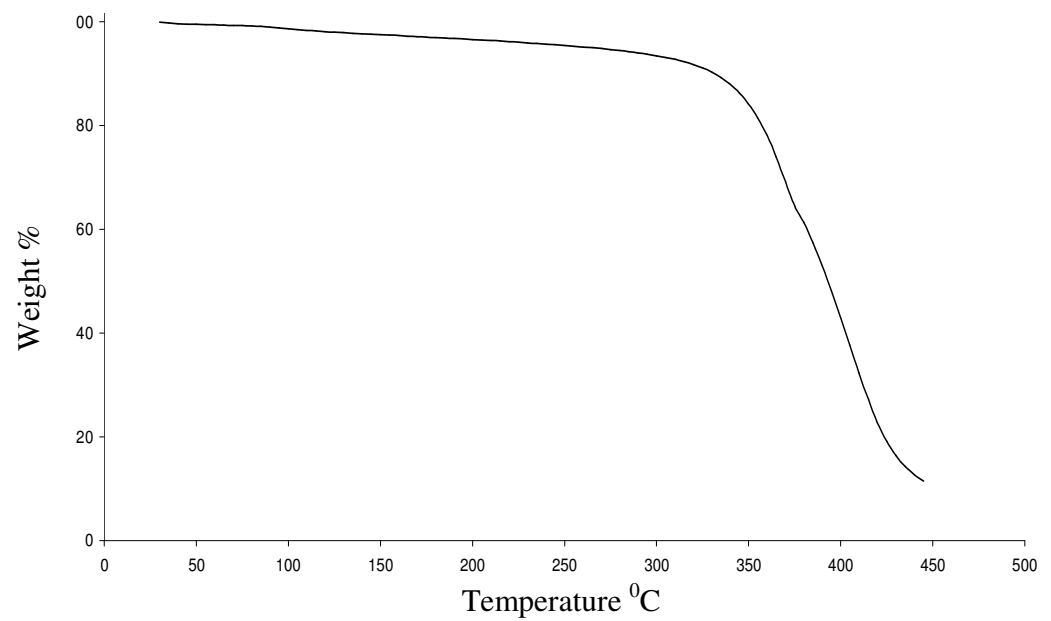

Figure 3. TG curve of epoxy acrylate with EOPA sample $\mathrm{R}_{1} \mathrm{M}$.

Table 2. Temp. of $1-10 \%$ loss in TGA (Program rate $10^{\circ} \mathrm{C} / \mathrm{min}$.) of cured epoxy acrylate resin of different acid values containing EOPA.

\begin{tabular}{cccc}
\hline & \multicolumn{3}{c}{ Temperature ${ }^{0} \mathrm{~K}$} \\
\cline { 2 - 4 } Wt. loss & R1M & R2M & R3M \\
\hline 1 & 363 & 373 & 369 \\
2 & 393 & 423 & 385 \\
3 & 448 & 463 & 397 \\
4 & 498 & 503 & 408 \\
5 & 538 & 533 & 448 \\
6 & 563 & 553 & 538 \\
7 & 580 & 570 & 566 \\
8 & 591 & 583 & 580 \\
9 & 598 & 592 & 589 \\
10 & 606 & 600 & 595 \\
\hline
\end{tabular}




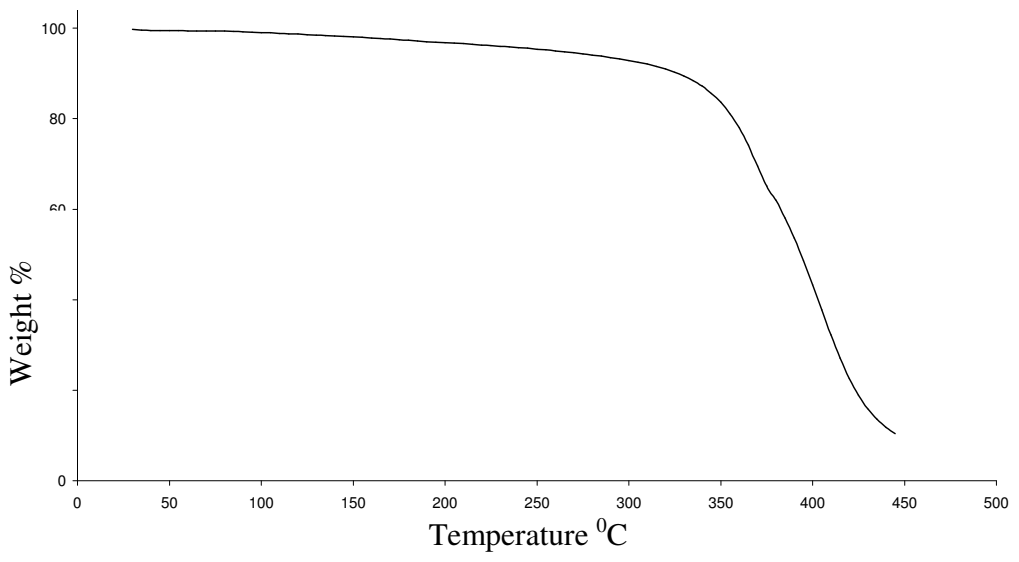

Figure 4. TG curve of epoxy acrylate with EOPA sample $\mathrm{R}_{2} \mathrm{M}$

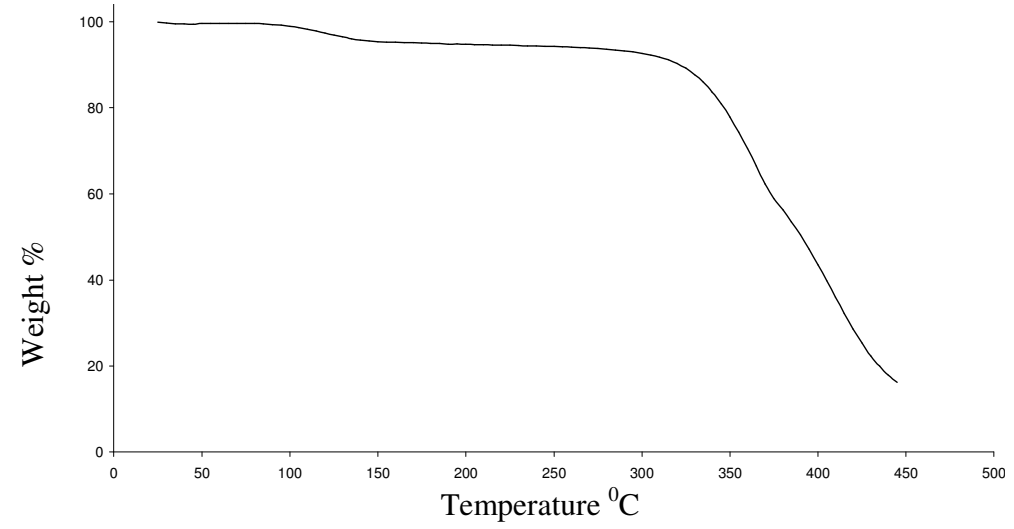

Figure 5. TG curve of epoxy acrylate with EOPA sample $\mathrm{R}_{3} \mathrm{M}$

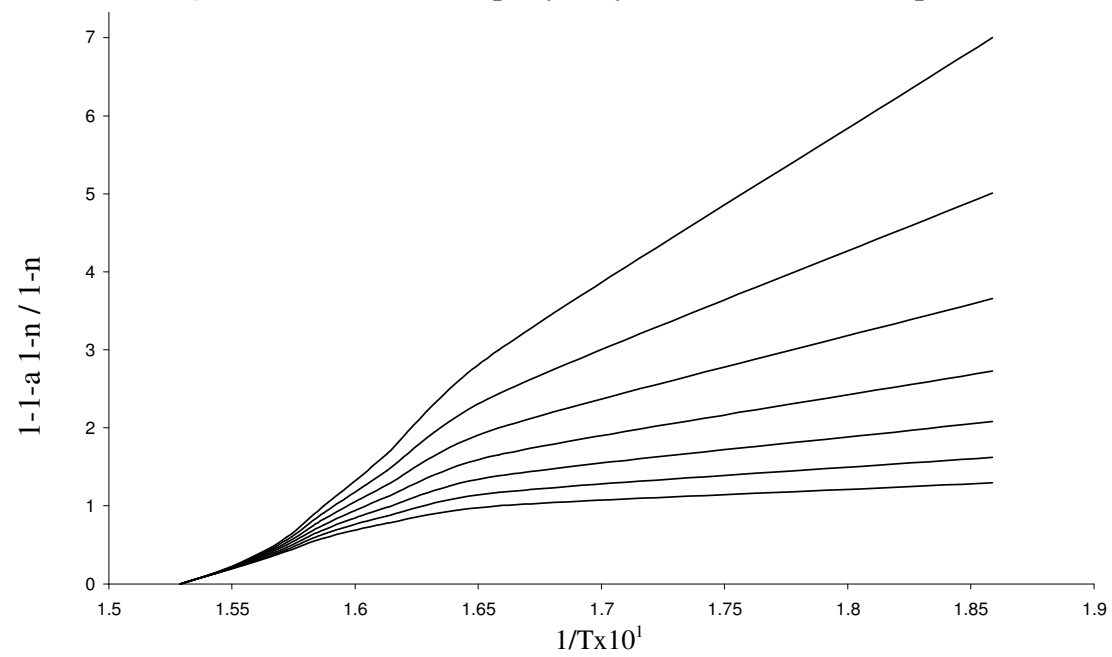

Figure 6. Plot between 1-1-a 1.n /1.-n and reciprocal of temperature from TGA data for $\mathrm{R}_{1} \mathrm{M}$ Step 1 . 


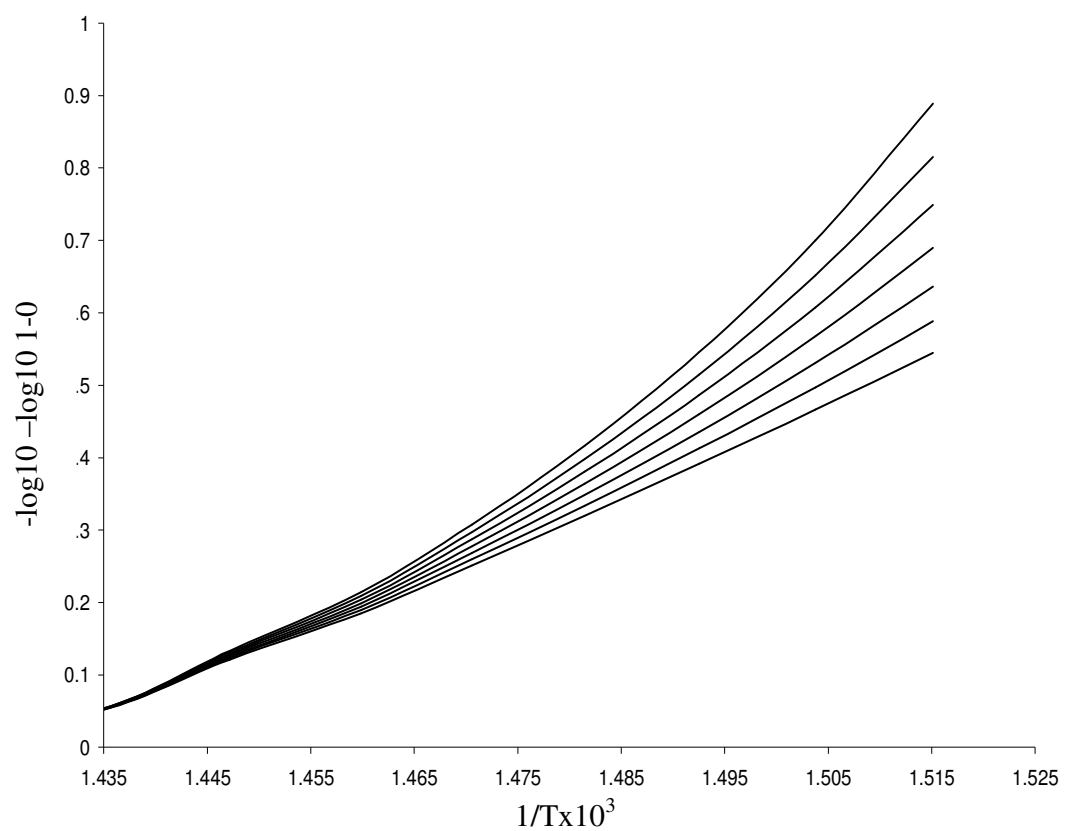

Figure 7. Plot between $-\log _{10}-\log _{10} 1-\mathrm{a}$ and reciprocal of temperature from TGA data for $\mathrm{R}_{1} \mathrm{M}$ step II

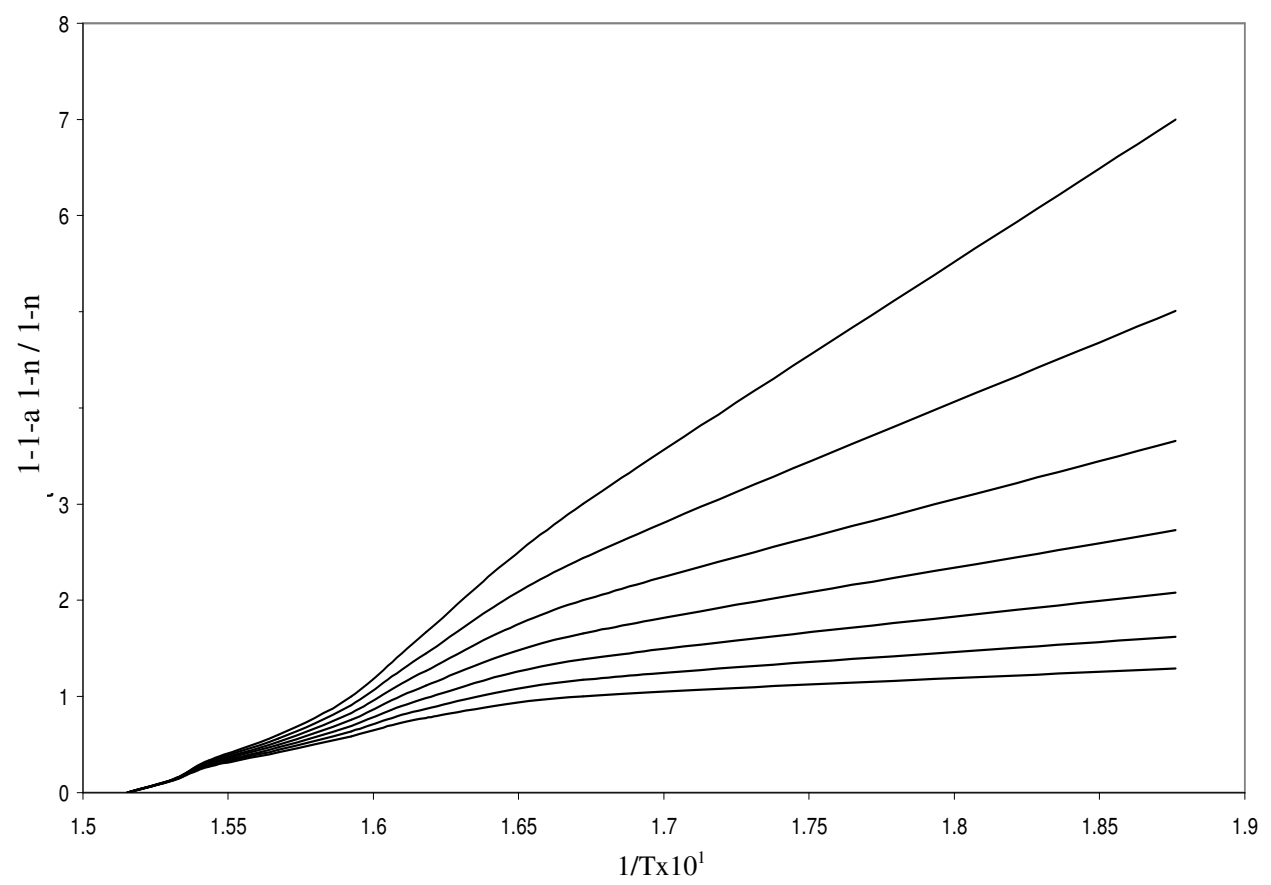

Figure 8. Plot between 1-1-a 1-n/1-n and reciprocal of temperature from TGA data for $\mathrm{R}_{2} \mathrm{M}$ step 1 . 


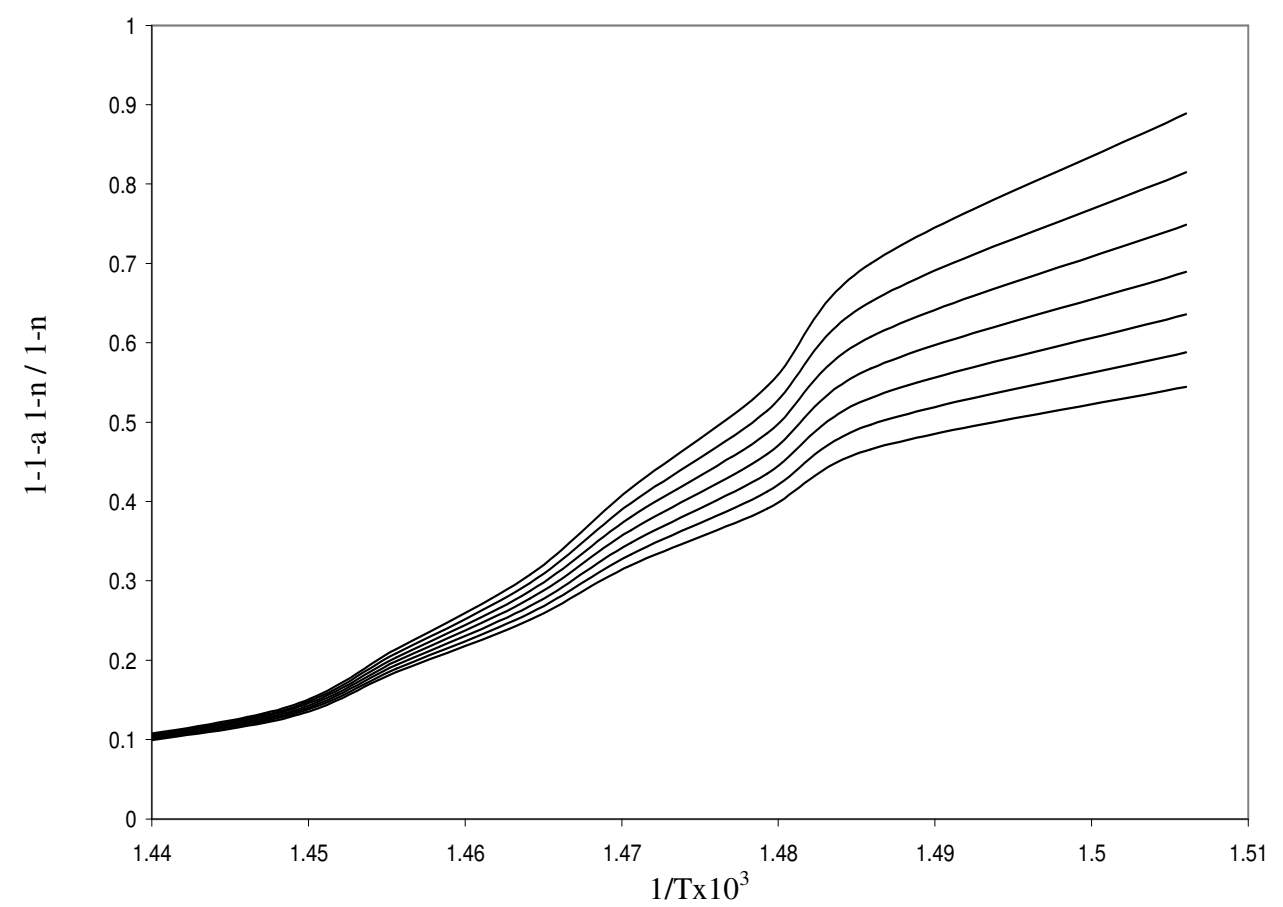

Figure 9. Plot between $-\log _{10}-\log _{10} 1$-a and reciprocal of temperature from TGA data for $\mathrm{R}_{1} \mathrm{M}$ step II

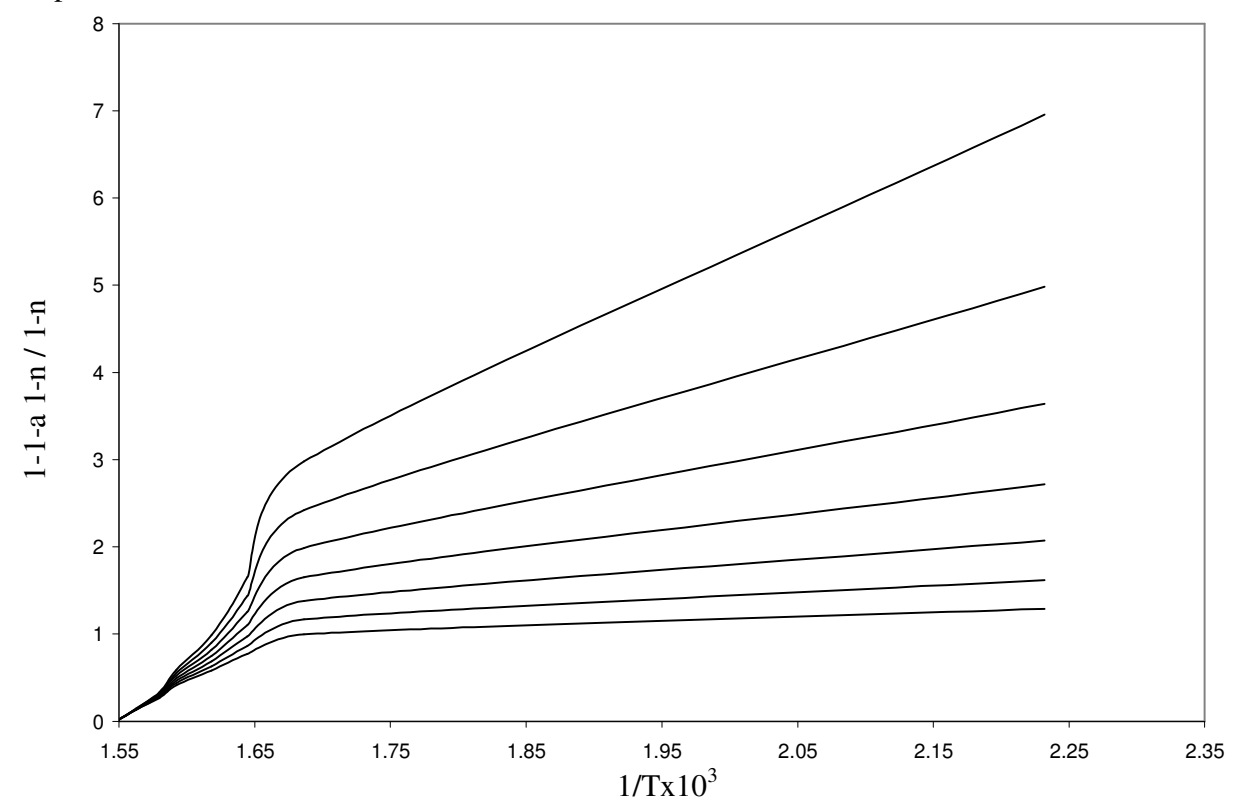

Figure 10. Plot between 1-1-a 1-n/1-n and reciprocal of temperature from TGA data for $\mathrm{R}_{2} \mathrm{M}$ step 1 


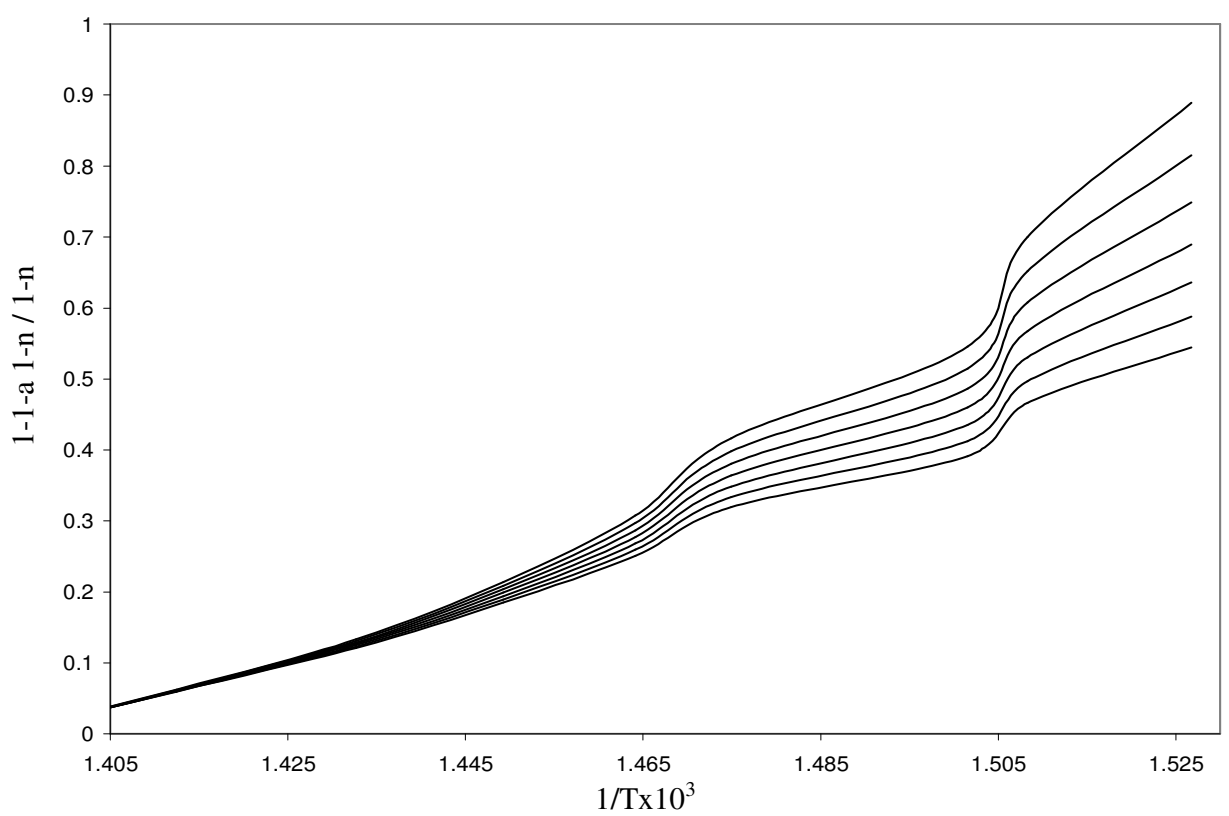

Figure 11. Plot between $-\log _{10}-\log _{10} 1-\mathrm{a}$ and reciprocal of temperature from TGA data for $\mathrm{R}_{1}$ M step II

The best fit value of $\mathrm{n}$ for all sets has been calculated in the 0-2 range by a computational technique. Statistical analysis of the TGA data in accordance with the Coats - Redfern equation was done by linear regression analysis which provides the best fit value of (n). In all cases for step I, it shows second order degradation kinetics except for $\mathrm{R}_{2} \mathrm{M}$ which shows 1.75 order degradation kinetics. For step II it shows half order degradation kinetics for R2M \& $\mathrm{R} 3 \mathrm{M}$ and for R1M it shows first order degradation kinetics. Correlation coefficient $\left(\mathrm{R}^{2}\right)$ of all samples showing higher value for $\mathrm{n}$ are discussed in Table 3. From the slop and intercept values, obtained from plots of different blend samples (Figure 6, 7, 8, 9, 10 \& 11) activation energy (E), pre exponential factor $(Z)$ have been calculated for $n=2$. It is clear from the Table 3 that the values of activation energy (E) and pre exponential factor $(Z)$ for $R_{1} M$ are higher as compared to $\mathrm{R}_{2} \mathrm{M} \& \mathrm{R}_{3} \mathrm{M}$ (for step I \& II) which is $420.56 \mathrm{KJ} / \mathrm{mol} \& 1.7 \times 10^{7}$ and $126.2 \mathrm{KJ} / \mathrm{mol} \& 1.36 \times 10^{6}$ respectively.

Table 3. Data of degradation kinetics for blends of epoxy acrylate resins and ethoxylated phenol mono acrylate $\left(\mathrm{R}_{1} \mathrm{M}, \mathrm{R}_{2} \mathrm{M} \& \mathrm{R}_{3} \mathrm{M}\right)$

\begin{tabular}{cccccccc}
\hline \multirow{2}{*}{$\begin{array}{c}\text { Samples } \\
\text { No. }\end{array}$} & Composition & \multicolumn{2}{c}{$\begin{array}{c}\text { Correlation } \\
\text { coefficient, } \mathrm{R}^{2}\end{array}$} & \multicolumn{2}{c}{$\begin{array}{c}\text { Activation energy, } \\
\text { E, KJ/mol. }\end{array}$} & \multicolumn{2}{c}{$\begin{array}{c}\text { Pre-exponential } \\
\text { factor, Z }\end{array}$} \\
\cline { 3 - 8 } & & I & II & I & II & I & II \\
\hline 1 & $\mathrm{R}_{1} \mathrm{M}$ & 0.9948 & 0.9876 & 420.56 & 126.2 & $1.70 \times 10^{7}$ & $1.36 \times 10^{6}$ \\
2 & $\mathrm{R}_{2} \mathrm{M}$ & 0.9944 & 0.9123 & 273.22 & 99.41 & $7.12 \times 10^{6}$ & $8.74 \times 10^{5}$ \\
3 & $\mathrm{R}_{3} \mathrm{M}$ & 0.9445 & 0.988 & 191.93 & 78.36 & $3.53 \times 10^{6}$ & $5.39 \times 10^{5}$ \\
\hline
\end{tabular}

Higher values of activation energy and pre exponential factor may be attributed due to the higher esterification in the sample having lower acid value. Higher activation energy and pre exponential factor for the decomposition of blends leads to better thermal stability of the compound. 


\section{Conclusion}

An attempt has been made to establish the correlation among the data obtained from different tests and to suggest how best the findings can be used in assessing the performance of coatings. The practical data obtained from some of the essential tests conducted on the unsupported and supported coatings were discussed to project their performance criteria. The data obtained from different test, shows that the UV curable formulations with lower acid value have good thermal behavior which may be due to the higher esterification during the reaction.

\section{References}

$1 \quad$ Lee H and Nevelle K, Handbook of epoxy resin, McGraw-Hill, 1972, pp. 1.

2 Oprea S, Vlad S, Stanciu A and Macoveanu M, Eur Polym J., 2000, 36, 373.

3 Cascaval C N, Rosu D and Stoleriu A, Polym Deg Stab, 1997, 55, 281.

$4 \quad$ Annelese E and Gerbase, Surf Coat Int., 2002, 8, 79.

5 Bajpai M, Shukla V and Kumar A, Prog Org Coat., 2002, 44, 271.

6 Agarwal D, Vasishtha A K, Surf Coat Int., 1983, 66, 1.

7 Weiss K D, Prog Polym Sci., 1997, 22, 203.

8 Haering E, Application of radiation curable coatings on metal substrates, Maecel Dekker, Inc, New York, 1984.

9 Goss B, Int J Adhes Adhes, 2002, 22, 405.

10 Green G E, Stark B P and Zahir S A, J. J Macromol Sci Rev Macromol Chem C., 1982, 21, 187.

11 Kloosterboer J G, Adv Polym Sci., 1988, 84,1.

12 Decker C, Viet T N, Decker D and Weber-Koehl E, Polymer, 2001, 42, 5531.

13 Zhang JY, Windall G and Boyd I W, Appl Surf Sci., 2002, 186, 568.

14 Narayan R, Doctoral Thesis, Submitted to ISM, Dhanbad, India.

15 Mehrotra K N and Rawat M K, Colloid \& Polymer Science, 1992, 270, 1232-1236.

16 Straszko J, Olszak-Humienik M and Mozejko J, J Therm Anal Calor., 1996, 48, 1415-1422.

17 Ian Hamerton, Alen M. Emsley, Brendan J Howlin, Paul Klewpatinond and Shinji Takeda, Polymer, 2004, 45, 2193-2199.

18 Salmoria G V, Gonzalez VJ, Ahrens C H, Soldi V and Pires A T N, J Mater Process Technol., 2005, 168, 164-171.

19 Karshak V V, Vinogradova, in: Burdon Ed., Polyesters, Pergamon Press, Oxford, 1965, p. 191. 


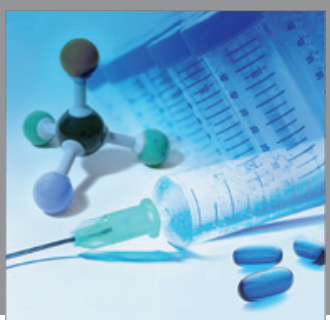

International Journal of

Medicinal Chemistry

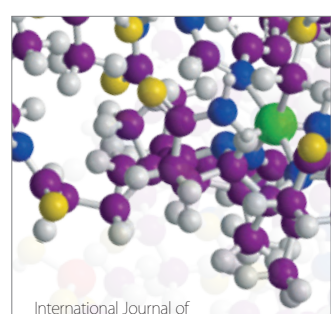

Carbohydrate Chemistry

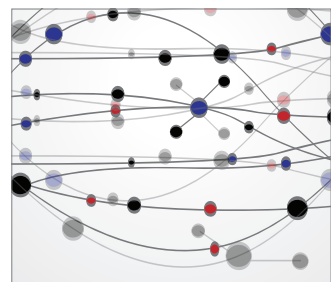

The Scientific World Journal
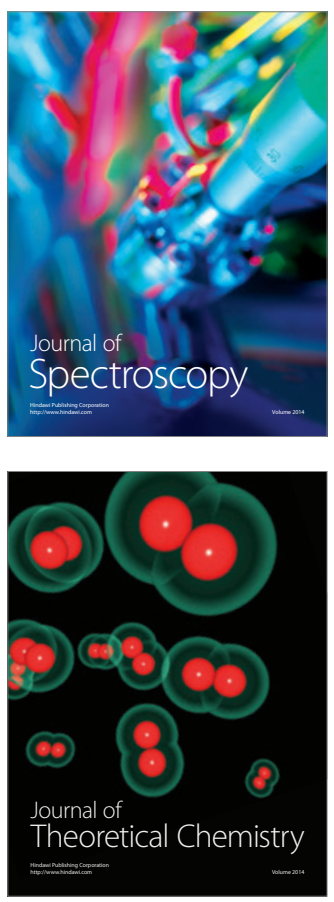
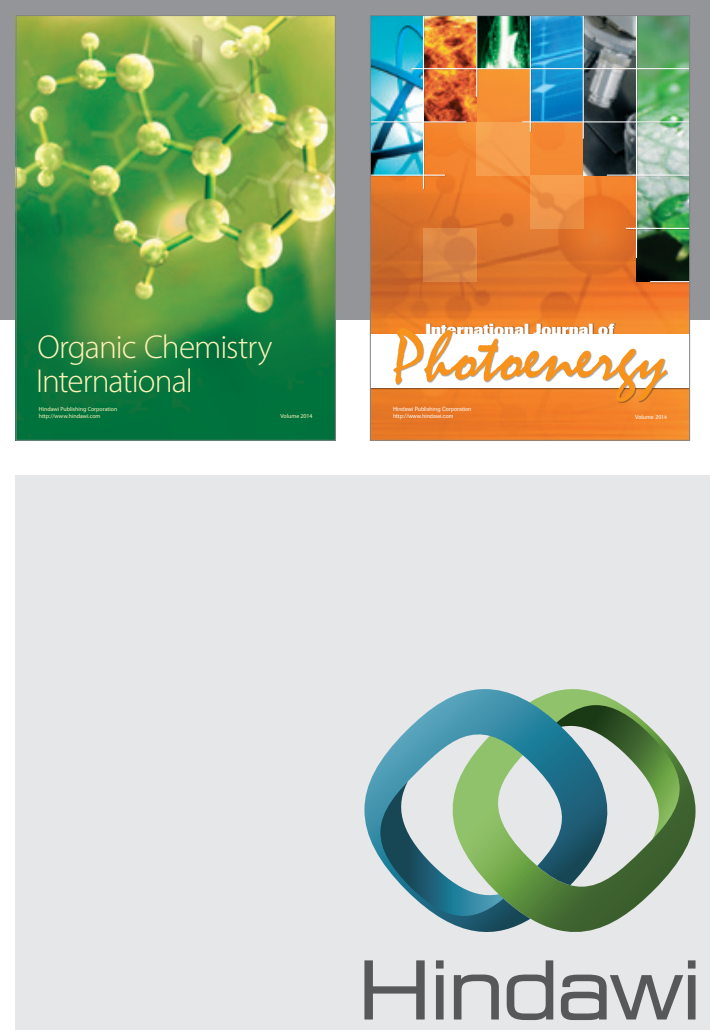

Submit your manuscripts at

http://www.hindawi.com
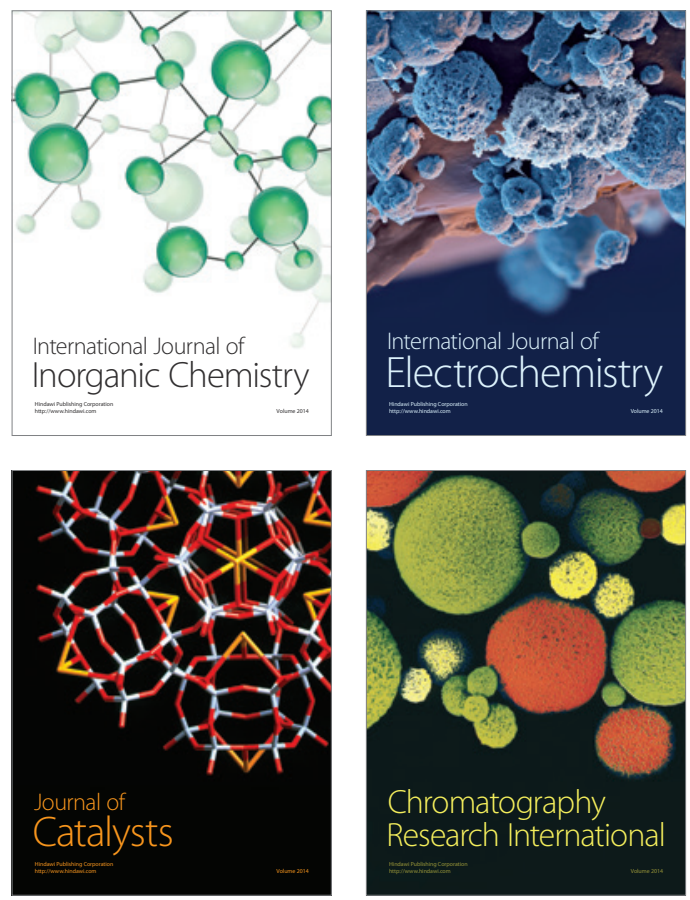
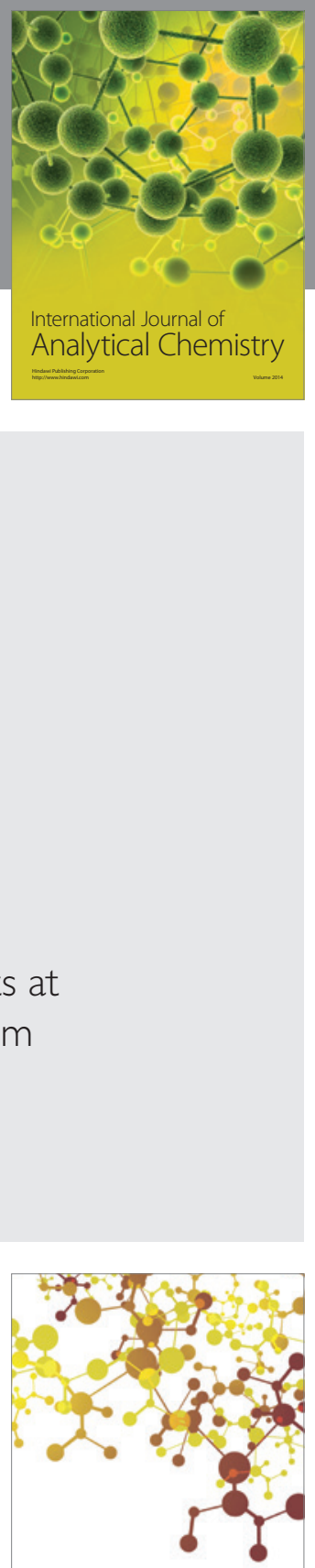

Journal of

Applied Chemistry
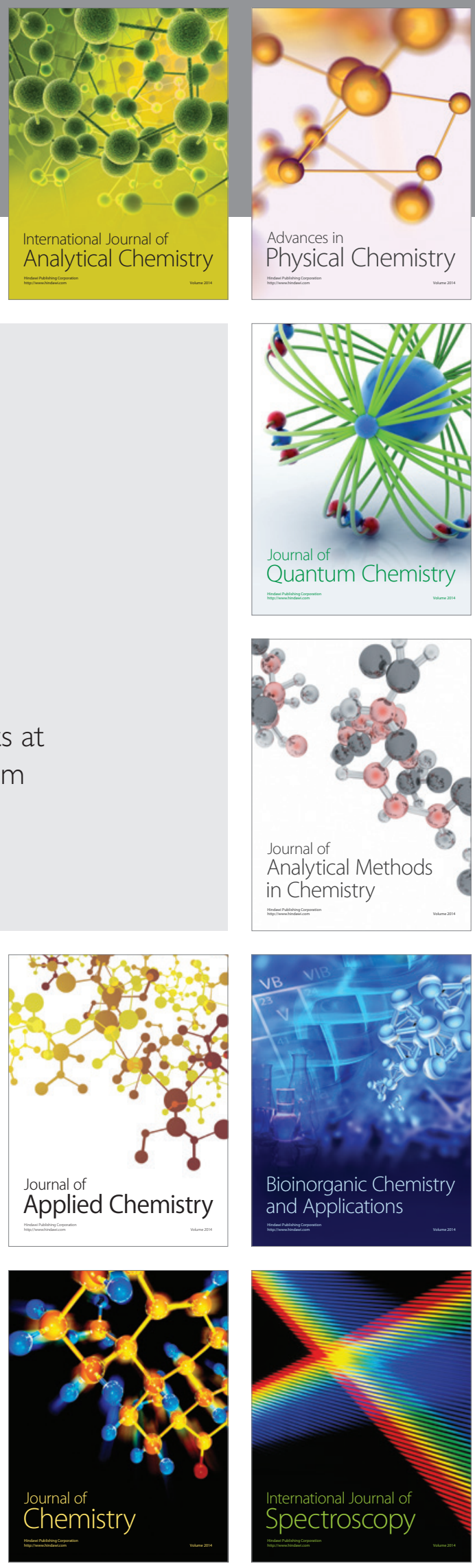